\title{
Trichotillomania in a patient with dementia: a case report
}

\author{
Praveen Navkhare, Abhishek Mamarde, Pankaj Bagde, Amit Nagarkar
}

\section{Summary}

Trichotillomania represents the symptom of pulling out hair. This has been recognised in many psychiatric disorders but is a relatively uncommon presentation.
We report a case of trichotillomania associated with dementia. Treatment with Selective Serotonin Reuptake Inhibitors was found to be effective.

SL J Psychiatry 2014; 5 (1):27-28

\section{Introduction}

Trichotillomania is defined as recurrent failure to resist the impulse to pull out hair associated with increased tension followed by relief or gratification after pulling out hair. It is categorised as an impulse control disorder (1). It is associated with different conditions such as Obsessive Compulsive Disorder (OCD), borderline personality disorder, depressive disorders, intellectual impairment, dementia and in post-encephalitic syndromes (2). Many patients with this disorder do not manifest all the Diagnostic and Statistical Manual of Mental Disorders- IV (DSM-IV) criteria or do so intermittently (3). The scalp is the most commonly involved site but most patients pull out hair from more than one site (4). The onset is generally in childhood or adolescence. However, we report a case of trichotillomania in a 72-year-old male with dementia.

\section{Case report}

A 72 year old right handed, married male was brought to a tertiary care centre for psychiatric disorders with complaints of irritability and plucking of hairs from his scalp of six months duration.

His complaints had begun two years previously with gradually progressive memory loss. Family members noticed a difficulty in conversing with the patient. $\mathrm{He}$ had difficulty in following instructions and misplaced personal belongings. His memory deteriorated progressively in the next year and he had difficulty in determining his whereabouts in his own house. His wife reported a deterioration in personal hygiene and an abandonment of personal interests. The forgetfulness, however, was not subjectively perceived by the patient. Over the previous six months, he had become increasingly irritable. He also began plucking his hairs out from his scalp. The frequency of this behaviour increased resulting in an irregular patch of baldness over the temporal-parietal region. There was no apparent precipitating event prior to these behaviours. There was no history of impulsive behaviors, and no other obsessive-compulsive behaviours. When asked for the reason for the frequent plucking of hair, the patient reported that he had intense itching over the

scalp. However, there was no associated rash, redness or other skin lesion in the affected scalp region. There was no family history of psychosis, OCD or dementia. Physical examination revealed patchy hair loss that involved the entire scalp. Neurological examination was unremarkable. On mental state examination, the patient was found to be conscious and well oriented. His speech was relevant and coherent. There were no affective symptoms or psychotic features. His attention span was found to be decreased and his immediate memory was impaired. His Mini Mental Status Examination (MMSE) score was $17 / 30$ and his score on the Geriatric Depression Scale was 4/30.

He was commenced on a cholinesterase inhibitor (donepezil) and a Selective Serotonin Reuptake Inhibitor (SSRI), fluoxetine.to which he responded with a reduction in the repetitive behaviour.

\section{Discussion}

Dementia presents with a variety of psychiatric disorders and behavioural disturbances, including depression, anxiety, psychosis, delirium, and aggressive behaviour (5). In this case, the patient presented with trichotillomania following a period of cognitive decline. Striato-thalamic-cortical-striatal pathways mediated by the putamen have been specifically implicated in ritualistic behaviors (6). Studies have demonstrated that trichotillomania subjects have decreased left putamen volume when compared with normal controls (7). We speculate that a similar pathology may be involved in trichotillomania when these circuits are damaged by degenerative processes, as that occurring in dementia. SSRI have been used in OCD and impulse control disorders. They act by blocking caudate nucleus activity, which then inhibits the activity of the globus pallidus, disrupting the striato-thalamic-corticalstriatal loop (8). SSRIs may have a similar action on putamen-mediated striato-thalamic-cortical pathways in trichotillomania which may explain the response to fluoxetine in this case. 


\section{References}

1. American Psychiatric Association. Diagnostic and Statistical Manual of Mental Disorders, 4th Ed. Washington, DC: American Psychiatric Association, 1994.

2. Christenson GA, Crow SJ. The characterization and treatment of trichotillomania. J Clin Psychiatry 1996; 57 (suppl 8):42-7; discussion 48-9.

3. Christenson GA, Mackenzie TB, Mitchell JE. Characteristics of 60adult hair pullers. Am J Psychiatry 1991; 48:365-70.

4. Kaplan HI, Sadock BJ (ed). Textbook of psychiatry. 6th ed. Baltimore: Williams and Wilkins; 1995:1412-15.

5. Lyketsos CG, Steinberg M, Tschanz JT, Norton MC, Steffens DC, Breitner JC. Mental and behavioral disturbances in dementia: findings from the Cache County Study on memory in Aging. Am J Psychiatry 2000; 157:708-14.

6. Martin J. Neuroanatomy Text and Atlas. New York: Elsevier Science Publishing, 1989.

7. O'Sullivan RL, Rauch SL, Breiter HC, et al. Reduced basal ganglia volumes in trichotillomania measured via morphometric magnetic resonance imaging. Biol Psychiatry 1997; 42:39-4

8. Baxter LR Jr, Schwartz JM, Bergman KS, et al. Caudate glucose metabolic rate changes with both drug and behavior therapy for obsessivecompulsive disorder. Arch Gen psychiatry 1992; 49:68. 